\title{
Niños: ¿ Precursores de la paz o de la guerra?
}

\section{Children: Precursors of peace} or war?

\author{
Laura Isabel Galarza Jiménez ${ }^{1}$
}

Amerikan Kültür Sede: Bornova, Turquía

\section{RESUMEN}

Educar a los niños para la paz o la guerra depende de que la sociedad, el gobierno, la familia, la escuela y los medios de comunicación tecnológicos trabajen conjunta y coherentemente, siendo modelos, tanto inmediatos como distantes, para ellos. La paz viene cuando la educación trabaja conjuntamente con los valores y es impedida cuando cualquiera de los que intervienen en ella no asume el papel de educador.

Abstract: Educating children for peace or war depends on whether society, government, family, school and technological social media work jointly and coherently, being models, both immediate and distant, for them. Peace comes 1 ORCID: https://orcid.org/0000-0002-3589-7036 Correo Electrónico: laigaji@hotmail.com Licenciada en Lenguas Extranjeras Inglés-Francés Universidad Santiago de Cali, Colombia. Profesora de Inglés y Español en Amerikan Kültür Sede: Bornova. Dirección: 1751 St. No: 16 k.13 Apartamento: 5 Mevlana, Izmir, Turquía Teléfono: (+90)5060952145 when education works together with values and is blocked when any of those involved in it do not assume the role of educator.

Palabras clave: Educación, aprendizaje, paz, guerra, niños.

Key words: Education, learning, peace, war, children.

\section{INTRODUCCIÓN}

Niños: ¿precursores de la paz o de la guerra? Esta pregunta nos lleva a enfocarnos en un gran número de aspectos ya que son muchos los que están involucrados en la vida de los más jóvenes. Estar en una temprana edad hace a los niños susceptibles a una increíble cantidad de factores de los que muchas veces los adultos no somos conscientes. Cómo la sociedad, el gobierno, la familia, la escuela y los medios de comunicación pueden dejar huella en nuestros infantes es algo que aún resulta imposible de medir haciendo igualmente arduo el decidir por 
cuál de ellos podemos encaminarlos y que sean formados para la paz o para la guerra.

Indagando acerca de la calidad que estos aspectos han alcanzado hoy en día y cómo los más jóvenes se están adaptando, se llega a la conclusión de que es imposible dividirlos ya que los niños hacen parte fundamental de cada uno. Así que comenzaré explicando cómo cada uno los afecta de manera positiva y negativa, separándolos en modelos distantes y modelos inmediatos; $y$ tal vez al final podamos reflexionar en si estamos instruyendo soldados para lo que llamamos "el bien común" -que se traduce en defender los intereses privados de otros- 0 si estamos formando pacifistas que puedan cambiar la historia del mundo conocida hasta ahora.

\section{SOCIEDAD $Y$ GOBIERNO (MODELOS DISTANTES)}

\section{"No puede haber una revelación más intensa del alma de una sociedad que la forma en que se trata a sus niños"}

-Nelson Mandela, ex presidente de Sudáfrica.

Mucha gente manifiesta que padre y maestros tienen la responsabilidad primaria en el desarrollo individual de los niños (Clipa, O. \& lorga, A. 2012) e incluso cuando aquello es una verdad parcial que no todas las familias o profesores han internalizado, es un pensamiento que ha direccionado al resto de nosotros -los que no somos padres o maestros-a asumir una postura cómoda dando por sentado que su educación no tiene que ver con nosotros.

¿Cuántas veces nos hemos detenido a considerar lo que un niño pensará de nosotros haciendo esto o aquello? Pocas veces, en realidad, por no decir nunca. $Y$ tal vez esa es la razón por la que ellos piensan que es correcto e incluso astuto sacar provecho de otros; que está bien y es normal pensar en mí y lo que es de mi propiedad primero antes de considerar las necesidades de mi prójimo. Está bien entonces ser irreverente cuando estoy de mal humor e incluso el agredir a los que no están de acuerdo conmigo o prefieren otro equipo de futbol que no es el mío. Es bien visto y nada raro el fumar, beber o consumir drogas para liberar algo de estrés en nuestras vidas. Éstos son algunos de los ejemplos que reciben los niños de la sociedad actual.

¿Qué puede pensar los más jóvenes cuando su país marcha a la guerra? Tal vez que es más fácil apoderarse de un montón de armas de última tecnología y abalear a quienes nos ofenden que tratar de conciliar. Que si persisten en comunicarse asertivamente con sus contrarios los hará ver débiles ante los demás. O tal vez, tratarán de hablar con ellos pero al no lograr un acuerdo tienen excusa para proceder a violentarlos.

Todo país que escoge la guerra sobre la paz como solución a sus problemas piensa que están defendiendo lo que es de ellos y que aciertan al hacerlo; pueden ofrecer una extensa lista de razones por las cuáles ellos están en lo correcto y sus oponentes no.

¿Cuál es entonces la raíz de este problema? ¿Falta de tolerancia?

No muchas veces hemos cavilado en lo que esa simple palabra comprende. Pensamos que ser tolerantes es sólo entender y respetar las opiniones ajenas. Al buscar sinónimos y definiciones he encontrado, entre muchas, las siguientes, las cuales asumen un enfoque pasivo:

- Una actitud justa, objetiva y permisiva. ${ }^{2}$

- Respeto a las ideas, creencias o prácticas de los demás cuando son diferentes o contrarias a las propias. ${ }^{3}$

\footnotetext{
2 Dictionary.com

3 Real academia de la Lengua Española. http:// dle.rae.es/?id=ZyWPzRW
} 
Entonces, ¿debo aceptar y respetar la opinión de la persona que piensa que los inmigrantes deben ser expulsados de su país porque están reduciendo las vacantes de empleo para los oriundos? $\mathrm{O}$ ¿debo continuar siendo permisiva y objetiva con prácticas religiosas que vulneran los derechos humanos como los casos de mutilación de genitales femeninos en países de África, Asia y el Medio oriente sólo porque es la insensata tradición de comunidades locales?

Si bien, la tolerancia hace parte importante de la educación para la paz, es imperante adoptarla desde un enfoque activo y de la mano con el sentido crítico, tal como lo expresa Arboleda (2016) "la tolerancia es una manera de ser crítico edificador en la vida; de actuar inclusivamente con base en el reconocimiento y aceptación de sí mismo y del otro; pasa por reconocer que el mundo es asimétrico, que todos los individuos humanos no son iguales ni tienen porqué serlos, que el otro es diferente en pensamiento, forma de ser, actuar, obrar, sentir y percibir. También se es crítico cuando se reconocen y aceptan los aciertos, errores, limitaciones, debilidades y potenciales propios".

Si se obra desde este punto de vista, usando la crítica para examinar mi conducta y la de otros, se podrá llegar a la conclusión de que no podemos ser tolerantes pasivos frente a acciones o personas que profanen y violen los derechos humanos, pero adoptándola con un sentido activo y crítico éstas prácticas antes mencionadas no tendrían cabida, si quiera, en un mundo que educa para la paz.

Sin embargo, la tolerancia no es la solución única que determina la creación de agentes de paz o guerra ni su escases es el principal ingrediente para escenarios bélicos. Lo cual nos lleva al segundo problema que mantiene a la población infantil apartada del camino de la paz: Falta de buen ejemplo.
Los niños nunca han sido muy buenos para escuchar a sus mayores, pero nunca han fallado en imitarlos.

\section{James A. Baldwin}

No es suficiente el decir a los menores lo que es correcto y lo que no si con nuestras acciones contradecimos nuestras palabras. Ellos necesitan ver a los que los rodean llevando lo que dicen a sus acciones. Como alguien lo expresó antes en una frase: "Los niños son grandes imitadores. Así que démosles algo grande que imitar"4

\section{FAMILIA, ESCUELA $Y$ MEDIOS DE COMUNICACIÓN TECNOLÓGICOS (MODELOS INMEDIATOS)}

En consecuencia, necesitamos ahondar en los modelos más inmediatos o cercanos de los cuales los niños están rodeados, estos son: la familia, los medios de comunicación especialmente los tecnológicos- y la escuela.

Comenzaré con la escuela y los medios de comunicación tecnológicos pues como se mencionó anteriormente: la sociedad considera a la familia y maestros los responsables de la educación infantil y no obstante, muchos padres hacen caer gran parte de este compromiso a los docentes. Siendo familia y escuela los modelos más inmediatos de los menores, "en la actualidad se hace necesario cada vez más el desarrollo de habilidades para la vida, cimentado en un proceso de enseñanza -aprendizaje desde temprana edad, incluyendo además de la escuela, a la familia como eje del desarrollo de pensamientos que le permitan acceder a todas las estrategias y herramientas para analizar, reflexionar, crear e innovar con una mirada crítica, en cada situación" (Arboleda 2016). Partiendo de la familia y escuela trabajando de la mano para este fin, éstas a su vez impactarán en la sociedad y el gobierno creando mejores líderes y ciudadanos por ende.

4 Anónimo 
¿Qué es educación? ¿Cómo estamos formando a los menores en las escuelas?

La Conferencia Mundial sobre Educción de 1990 (EFA 1990) define la educación básica como la unión de las herramientas esenciales de aprendizaje (tales como la alfabetización, la expresión oral, la aritmética y la resolución de problemas) junto con los contenidos básicos de aprendizaje (como el conocimiento, habilidades, valores y actitudes) requeridas por los seres humanos para ser capaces de sobrevivir, desarrollar todas sus capacidades para vivir y trabajar con dignidad, participar plenamente en el desarrollo, mejorar la calidad de sus vidas, tomar decisiones informadas y continuar aprendiendo. ${ }^{5}$

Siempre he sido defensora de la declaración que expresa la Educación como la solución a muchos de los problemas que una sociedad enfrenta y por ende tiene el poder de transformar seres humanos y formar niños para un país pacífico pero, desafortunadamente, está sujeta a tantas condiciones que hacen imposible alcanzar este objetivo. Tomemos por ejemplo: ¿Cuántos niños en el mundo tienen acceso a la educación? $Y$ para aquellos que lo tienen, ¿Cuántos de ellos pueden acceder a una buena o alta calidad educativa? ¿Qué cantidad de maestros calificados tenemos en las escuelas? ¿Con qué frecuencia las escuelas innovan en currículo?

El acceso a la educación ha sido obstaculizado por diversos problemas sociales $y$ ha imposibilitado también alcanzar aquellos países donde conflictos armados tienen lugar. Siendo la destrucción de escuelas, la insuficiente cobertura, la explotación infantil, la caza de niños soldado junto con las escuelas y maestros convertidos en objetivos expresos y accidentales en tiempo de guerra son algunos de los problemas que la pedagogía enfrenta.

$5 \quad \underline{\text { http://www.ohchr.org/EN/Issues/Education/Train- }}$ ing/Compilation/Pages/9. WorldDeclarationonEducationforAll(1990).aspx
"UNICEF estima que poco más de mil millones de niñas y niños viven en países o territorios afectados por conflictos armados, y de estos, alrededor de 300 millones tienen menos de cinco años (Oficina Internacional de los Derechos del Niño, 2010). De hecho, aproximadamente la mitad de los 104 millones de niños en el mundo que no asisten a escuelas viven actualmente en países que se están recuperando de conflictos violentos 0 estados igualmente frágiles (UNESCO, 2004)". 6

El hecho de que los maestros no estén yendo a donde más los necesitan es lamentable. Países con problemas sociales más pronunciados y en estado de guerra son destinos evitados por docentes al no ofrecer las condiciones y materiales necesarios para el proceso de enseñanza-aprendizaje. $Y$ aún un gran número de los territorios que son considerados como ideales para residir no ofrecen innovación ni cambios significativos en programas educativos - currículos lo que significa que estamos enseñando lo mismo que enseñaron cincuenta años atrás o más cuando no tenían las ventajas, desventajas ni escenarios ahora existentes lo cual da como resultado el tener más estudiantes reprobando al intentar incrustarlos en un modelo obsoleto que no funciona ya para estos tiempos.

Como lo expresa OECD (2016) "las tecnologías digitales tienen un profundo impacto (...) en sociedades y están cambiando la manera en que trabajamos, nos comunicamos, participamos en actividades sociales y disfrutamos"7. Las consecuencias de esto han sido cuantiosas y a veces paradójicas, por citar algunos tenemos que:

$\checkmark$ La tecnología nos ha dado la oportunidad de estar en contacto y conocer todo tipo de

$6 \quad$ https://www.beyondintractability.org/library/roleeducation-build-peace-and-reconciliation-post-conflict-settings

7 OECD (2016), Innovating Education and Educating for Innovation: The Power of Digital Technologies and Skills, OECD Publishing, Paris. http://dx.doi. org/10.1787/9789264265097-en 
personas alrededor del mundo pero aun así, seguimos recurriendo en la xenofobia, la discriminación, el sexismo y el aislamiento.

$\checkmark$ Se nos ha brindado rápido y fácil acceso a la información pero nosotros y nuestros niños todavía no sabemos acerca de la historia del mundo, problemas del pasado que aquietan y afectan aún nuestras comunidades e incluso sobre nuestros verdaderos orígenes.

$\checkmark$ Podemos apreciar cantidad de videos, imágenes y escritos acerca de una variedad de temas pero no somos conscientes de que los más pequeños estén viendo los contenidos apropiados o no.

Por supuesto que el internet es un arma poderosa que puede ayudarnos a crear agentes de paz pero esto no pasará si no la usamos como complemento para hacer lo acertado. Por lo tanto, la tecnología en las escuelas es sinónimo de expansión del conocimiento pero éste sin valores es como tener la tierra pero no el agua para cultivar.

"Mientras tratamos de enseñarles a nuestros hijos todo sobre la vida, nuestros hijos nos enseñan de qué se trata la vida". -Ángela Schwindt, madre de escolarización en el hogar.

Podemos enseñar valores en la escuela, por supuesto, pero la fuente principal de estos es la familia.

Los colegios se han convertido en el depósito de niños para ciertos padres que no quieren lidiar con ellos por mucho tiempo. He tenido demasiados padres que me han dicho orgullosamente cómo sus hijos asisten a clases de deportes, música, baile, pintura y toda clase de actividades extracurriculares que sólo puedo preguntarme ¿Cuánto tiempo de sobra tiene este niño para pasar tiempo con sus padres entonces? ¿Qué clase de tiempo de calidad pueden ofrecerle a un niño que tiene una agenda atiborrada?
Aun cuando los padres tienen la mejor intención con respecto a la formación de sus hijos, muchas veces no llegan a comprender que llevando ese tipo de actividades al extremo están renunciando a ser modelos inmediatos para sus hijos y concediendo este beneficio a extraños -quienes no siempre tienen los valores que queremos que ellos aprendan- para que sean el ejemplo de sus hijos.

En contraste, aquellos padres que no poseen los ingresos necesarios para pagar por rellenos de tiempo para sus hijos o aquellos que no comparten el tiempo de calidad necesario con ellos recurren en su mayoría en el problema de ser malos ejemplos para los infantes. En este ajetreado nuevo mundo es común que los progenitores trabajen largos turnos y lleguen a casa tan fatigados y exasperados que no tienen ni siquiera el tiempo, la oportunidad o la disposición para preguntarse lo que hicieron o están haciendo sus hijos o lo que están viendo y aprendiendo de ellos en ese momento.

Con lo cual es normal el tener padres preocupados porque sus hijos dicen vulgaridades en clase, cuando tal vez es que nos han oído insultando al vecino o al jefe en casa. O lucen sorprendidos cuando los docentes les informamos del matoneo que lleva a cabo su hijo a un compañero y es solamente el niño imitándoles cuando desaprueban y repudian a personas que son diferentes en color, raza, religión u orientación sexual.

A menudo no somos conscientes del rol tan fundamental que tienen los menores en la creación del nuevo mundo y el efecto que tenemos sobre ellos. Siempre se oye decir que el niño de hoy es el hombre del futuro pero no les estamos brindando los medios para ser parte del cambio. Estamos sólo enseñando lo que nuestros padres y abuelos nos enseñaron, repitiendo las mismas palabras y acciones que escuchamos y vimos en ellos o dando a otros la totalidad de la responsabilidad de educarlos. 
Aún nuestros menores están aprendiendo que la violencia es la solución más rápida y efectiva a los problemas cuando somos el resto de nosotros quienes tenemos que internalizar que la educación, con todo lo que involucra, es la mejor vía.

¡Por lo tanto, sí! La educación es el camino más potente y efectivo para formar a los precursores de la paz pero sólo funcionará cuando entendamos que yo, usted y todas las personas en el mundo somos educadores, entendiéndose el término como quien promueve por excelencia el desarrollo de la comprensión, es decir del conjunto de capacidades, actitudes, valores y disposiciones para que los sujetos educables se apropien afectiva, cognitiva y críticamente del conocimiento, y lo usen de manera edificadora en diversos contextos incluido el de la vida, aportando ideas $y$ acciones para construir mundos mejores, más dignos. (Arboleda, 2011)

Quiero finalizar con dos frases que resumen la idea de mi anterior perorata.

"Los niños son el mensaje viviente que enviamos a un futuro que no veremos" -_John F. Kennedy, $35^{\circ}$ presidente de los Estados Unidos.

"Dado que la guerra comienza en la mente del hombre, es en la mente del hombre donde se debe construir la base de la paz" - (UNESCO, 1947)

\section{REFERENCIAS BIBLIOGRÁFICAS}

ARBOLEDA, J. (2011) "COMPETENCIAS PEDAGÓGICAS I. Conceptos y estrategias para el fortalecimiento, evaluación y comprensión de la práctica formativa", Editorial REDIPE, Colombia.

ARBOLEDA, J. (2016) "Textos Académicos. La Reseña Crítica, La Relatoría Y El Ensayo: Fundamentos y aplicaciones", Editorial REDIPE, Colombia.
CARR, K. (2013) "Effects of violence prevention programs on middle and high school violent behaviors" Northem Michigan University.

OECD (2016),"Innovating Education and Educating for Innovation: The Power of Digital Technologies and Skills", OECD Publishing, Paris.

WEBB-HAPERN, L. (2003) "The effects of higher education on tolerance: An investigation of political and cultural attitudes of college students"

\section{WEBGRAFÍA}

https://www. beyondintractability.org/library/roleeducation-build-peace-and-reconciliation-postconflict-settings

https://www.hsu.edu/academicforum/20032004/2003-4AFTheEffectsofHigherEd.pdf

https://www.tandfonline.com/doi/full/10.1080/00 309230.2015.1133679

https://www.ted.com/talks/geoffrey_ canada_our_failing_schools_enough_is_ enough\#t-745840

https://www.nmu.edu/education/sites/ DrupalEducation/files/UserFiles/Carr_ Kimberlee_MP.pdf

https://bold.expert/educating-the-21st-centurychild/

https://www.bartleby.com/essay/Are-ChildrenSmarter-Because-the-Internet-F3K8EJNBC

https://www.compassion.com/poverty/famousquotes-about-children.htm

https://www.brainyquote.com/es/citas/james-abaldwin_121311

https://www.beyondintractability.org/library/roleeducation-build-peace-and-reconciliation-postconflict-settings 